\title{
Mídia e educação em Portugal: campos em confronto
}

\author{
Antonio Francisco Ribeiro de Freitas
}

\section{Resumo}

Este artigo objetiva refletir sobre as visões divergentes que a cobertura midiática das questões educativas vêm provocando em Portugal. Os teóricos da Educação argumentam que os comentadores ou articulistas portugueses mais influentes, que atuam nos jornais Expresso e Público, são parciais em suas análises, estão a serviço do neoliberalismo e desqualificam constantemente a atividade docente, bem como a produção dos investigadores da Educação. Enfim, o presente trabalho objetiva desvelar os conflitos existentes hoje nos campos da Mídia e da Educação na sociedade portuguesa.

Palauras-chave:

Mídia, Jornalismo, Discurso midiático

\section{Some questions about the comtemporary journalist identity}

\section{Abstract}

Sobre 0 autor Pós-Doutor em Educação e Mídia pela Universidade do Porto, Potugal. Professor da Universidade Federal de Alagoas. afrf@decos.ufal.br
This article aims to reflect divergent views on the media coverage of education issues are causing in Portugal. The Education theorists argue that the commentators or Portuguese articulistas more influential than work in newspapers Public and Express, are partial in their analysis, are at the service of neoliberalism and disqualify constantly teaching and the production of researchers Education. Finally, the present study aims to unveil the conflicts existing today in the fields of Media and Education in the Portuguese society.

Key words:

Media, Journalism, Media and language 
A cobertura midiática das questões educativas em Portugal vem chamando a atenção da opinião pública, em razão da importância do tema, cujo debate ganhou espaço na mídia a partir das reformas educativas realizadas por meio da lei de Bases número 48 de 14 de outubro de 1986. Até então, Portugal não possuía um plano nacional definidor das diretrizes gerais no campo educativo. E, somente após longos e intensos debates políticos, a lei de bases 46/86 que estrutura o ensino português foi aprovada.

Destacamos que, somente após os desbobramentos da Revolução de 25 de abril de 1974, conhecida como a Revolução dos Cravos, os grupos políticos que assumiram os governos nos períodos revolucionário e pós-revolucionário apresentaram um projeto de planificação escolar.

Tal aprovação possibilitou a abertura de uma perspectiva mais democrática do campo educacional para as camadas populares da sociedade portuguesa, conforme argumentam os teóricos educacionais. A Educação, nessa altura, era atrelada aos preceitos do Estado Novo salazarista, com fortes traços de autoritarismo e elitismo. Educação esta que, segundo os investigadores das Ciências da Educação, excluía a maior parte dos jovens portugueses da escola, pois a escola era privilégio da elite que detinha o poder.

No entanto, em razão das dificuldades para se implantar, na prática, as mudanças educativas constantes na lei de Base 48/86, as desejadas reformas caíram em descrédito junto à sociedade portuguesa. Principalmente junto aos pais de alunos, professores, sindicatos dos professores e alunado. E para equacionar o problema, em 1996 o governo promoveu uma série de negociações políticas com a sociedade, objetivando uma parceria que permitisse efetivar as medidas de maior impacto no campo educacional, editando naquele ano um documento conjunto denominado de Pacto Educativo.

Porém, em razão dos sucessivos governos, ora de tendências mais à esquerda, ora mais à direita do espectro político, o desejado pacto educativo assinado em 1996, que visava implementar com mais rapidez as mudanças educativas definidas em 1986, não foi efetivado, o que faz com que as reformas continuem sendo um tema em aberto.

Ao longo desse debate, os meios de comunicação social, que refletem e refratam a seu modo os fatos da agenda social, ampliaram para o espaço público os principais pontos sobre as reformas educativas. Em outras palavras, as reformas educativas ganharam espaço na mídia, principalmente na mídia impressa, que por meio de alguns repórteres especializados e comentadores ampliaram o debate educativo.

Várias matérias passaram a ser veiculadas pela imprensa sobre a temática educacional, contendo principalmente opiniões contrárias às propostas educativas, que estavam inseridas no projeto inicial

Estudos em Jornalismo e Mídia - Ano V - n. 2 pp. XX - XX jul./ dez. 2008 
das reformas de base de 1986. Muitas matérias criticavam também as "reformas das reformas", que eram gestadas no âmbito do Ministério da Educação, pelos diversos governos que assumiram os destinos do país após a Revolução dos Cravos em 1974.

Uma das críticas principais presente no debate midiático é contra a permanência, no âmbito dos ensinos fundamental e médio, da teoria pedagógica Construtivista. Esta teoria, segundo alguns comentaristas, é a responsável direta pelos baixos índices de aproveitamento em Matemática e Língua Portuguesa que os alunos portugueses apresentam atualmente. Além da crítica à teoria pedagógica Construtivista, uma corrente de comentadores influentes apóiam, em seus artigos, a avaliação e o ranqueamento das escolas por meio de métodos que, segundo os téoricos da Educação, não levam em conta os contextos da comunidade escolar avaliada.

Além desses assuntos, muitos outros temas do campo educativo ganharam destaque na midia. Dentre eles merecem ser citados: o aumento da indisciplina nas escolas, as questões curriculares e as formas e tipos de avaliação, a redução da autoridade do professor, a massificação do processo de escolarização, uma vez que a partir da reforma educacional, um maior número de alunos das classes populares passaram a ter acesso à escola. Tais motivos somados, segundo alguns jornalistas, provocaram a queda do nível educacional em Portugal.

Por sua vez, um significativo grupo de acadêmicos e teóricos da Educação argumentam que, a partir da Revolução dos Cravos em 1974 e da reforma do sistema educacional em 1986, milhares de jovens, antes excluídos da escola, passaram a ter acesso à escolarização - acabando com a concepção elitista até então existente, quando somente os filhos da classe média tinham acesso à escola.

No decorrer do debate, os acadêmicos afirmam que quase não têm espaços na midia para emitirem seus pontos de vista, para contestarem os argumentos dos comentadores dos dois principais jornais do país - o jornal Público e o jornal Expresso. Em razão desse embate, argumentam que a informação jornalística é quase sempre de mão única, pois a imprensa não dá o mesmo espaço e destaque para o contraditório. Afirmam que a midia constrói uma imagem negativa dos teóricos da Educação junto à opinião pública, uma vez que os articulistas dos jornais influentes, atribuem a crise do sistema de ensino português, em última instância, aos teóricos da Educação.

\section{Cobertura parcial}

Eles afirmam ainda que, ultimamente, a mídia realiza uma cobertura parcial e descontextualizada dos assuntos educativos. De nunciam que os principais comentadores sobre Educação não são da área de Educação, ou são economistas ou sociólogos. E admitem 
também que, em decorrência da forma como a cobertura midiática das questões educativas vem sendo feita, ela tem contribuído em grande parte para negativar a atividade docente, pois chega até mesmo a desqualificar o trabalho do professor, fato que gera baixaestima junto ao corpo docente.

Em razão do que aqui foi exposto, entendemos ser necessário os veículos de comunicação social terem em seus quadros jornalistas com formação especializada em Educação. A qualificação básica na área permitirá uma abordagem com mais competência teórica sobre o tema, o que não é possível ser conseguido por um jornalista generalista. Isso porque a qualidade da informação e a credibilidade jornalística, nos tempos atuais, passam também pela qualificação do profissional da midia.

Outra queixa recorrente que os teóricos da Educação fazem contra a mídia portuguesa é sobre o fato de que não há imparcialidade na cobertura midiática. Pois, conforme os depoimentos de vários acadêmicos, a imprensa portuguesa, na cobertura sobre as questões educativas, quase não cede espaço para o contraditório, levando ao leitor uma visão unilateral dos fatos.

Isso afeta a credibilidade do campo midiático, pois a informação de mão única vai contra o princípio básico da Deontologia da Comunicação Social, razão pela qual os jornalistas devem respeitar os compromissos ético-deontológicos no seu cotidiano. E outra constatação evidente é que o mito da imparcialidade ou da objetividade no jornalismo não se sustenta. Porque de forma implícita, ou muitas vezes explícita, a ação jornalística resulta de direcionamentos político-ideológicos, que confirmam a subjetividade do trabalho midiático e denunciam a presença dos filtros jornalísticos na produção noticiosa.

Por isso afirmamos que a mídia não é neutra, pois está sempre envolvida, metaforicamente, numa batalha retórica pela conquista de corações e mentes. Os veículos de comunicação social têm uma linha editorial que deve ser seguida pelos jornalistas - linha editorial esta que, em última análise, reflete os interesses do grupo político-ideológico-empresarial que dirige o meio de comunicação social. Ou seja, os grupos de comunicação social têm seus interesses políticos, econômicos e posicionamentos ideológicos de classe, que irão influenciar sempre as decisões editoriais.

Isso ocorre pelo fato de o campo midiático ser um campo de poder simbólico muito forte e presente na vida das pessoas, nomeadamente na sociedade midiática em que vivemos. Além disso, podemos concluir também que os jornalistas não são neutros. Motivo pelo qual ressaltamos que o discurso da imparcialidade da mídia é um mito que deve ser desfeito, pois tanto os pro- 
prietários dos meios, quanto os jornalistas, são parciais. Eles possuem desejos, pertencem a determinadas classes sociais, trazem determinados valores e intenções que são explicitados em seus discursos. Em outras palavras, possuem diferentes visões de mundo que marcam suas trajetórias enquanto sujeitos sócio-históricos. Motivo pelo qual afirmamos que nenhum texto é neutro, razão pela qual o leitor deve fazer sempre uma leitura crítica da mídia.

Por exemplo, há fatores jornalísticos que operam como filtros ou controle da informação, dentre os quais citamos os filtros jornalísticos destacados por Rossi (1986: 20): a pauta, o estilo, o copidesque, o editor, o diretor de redação, a chefia de reportagem, a produção do título, o tamanho do texto, o tamanho do título, a colocação do texto na página, a distribuição do título, as fontes, a empresa jornalística.

Outros fatores contribuem para o controle e o direcionamento da informação, tais como: o agenda setting, ou seja, a midia orienta as discussões no espaço público; o gatekeeper, que implica na ação do editor, como o selecionador privilegiado do fato e do destaque da notícia. Há ainda o fenômeno do newsmaking, isto é, a construção da notícia e da realidade social pelos midia e a angulação do tema pelo framing midiático, que implica na forma em que o assunto será mostrado ou tornado público. Portanto, em razão desses fatores afirmamos que há sempre parcialidade na produção jornalística.

Além dos fatores jornalísticos, lembramos a existência dos elementos lingüísticos, que são indicadores de subjetividade, tais como a apassivação, a polifonia, a citação direta, a citação indireta, a intertextualidade, a heterogeneidade discursiva, a citação do argumento de autoridade, a pontuação, a seleção lexical dentre outros, que fazem com que a parcialidade seja instaurada na produção discursiva da midia.

Finalmente, esperamos que este artigo sobre a análise da cobertura midiática das reformas educativas em Portugal possa contribuir tanto para a leitura crítica da mídia, quanto para o aprimoramento e aprofundamento do debate sobre esses dois campos de poder e de constituição social do conhecimento.

Compreendemos que esses campos são fundamentais para o desenvolvimento das consciências, visando a construção de novos sujeitos sociais e de outras possibilidades de sociabilidade no interior da sociedade do conhecimento e da comunicação. Concluímos que ambos os campos, Mídia e Educação, usam no seu cotidiano um elemento aparentemente simples e inofensivo - a palavra. Mas, a palavra, enquanto elemento semiótico em sua função de signo lingüístico, jamais é neutra.

Os jornalistas
possuem desejos,
pertencem a
determionadas
classes
sociais, trazem
determinados
valores e intenções
que são explicitados
em seus discursos




\section{Referências}

FREITAS, Antonio Francisco Ribeiro de. Discurso da mídia: um estudo de caso. Maceió: EDUFAL, 1999a.

Palavra: signo ideológico. Maceió: EDUFAL, 1999b.

A retórica jornalística: o persuasivo discurso da imprensa. Maceió: Ed.

Do Autor, 2007.

ROSSI, Clóvis. O que é jornalismo? 7 ed, São Paulo: Brasiliense, 1986.

Recebido em 30 de agosto de 2008

Aprovado em 25 de outubro de 2008 